\title{
Morfologia e topografia dos órgãos genitais masculinos externos da paca (Cuniculus paca Linnaeus, 1766)
}

\author{
Edson Moreira Borges ${ }^{1}$ \\ Érika Branco ${ }^{2 *}$ \\ Ana Rita de Lima ${ }^{2}$ \\ Leonardo Martins Leal ${ }^{3}$ \\ Leandro Luiz Martins ${ }^{3}$ \\ Ana Carolina Gonçalves Reis ${ }^{3}$ \\ Claudinei $\mathrm{Cruz}^{4}$ \\ Márcia Rita Fernandes Machado ${ }^{3}$ \\ Maria Angelica Miglino ${ }^{1}$ \\ ${ }^{1}$ Departamento de Cirurgia da Faculdade de Medicina Veterinária e Zootecnia \\ Universidade de São Paulo, São Paulo - SP, Brasil \\ ${ }^{2}$ Laboratório de Pesquisa Morfológica Animal da Faculdade de Medicina Veterinária \\ Universidade Federal Rural da Amazônia \\ Avenida Presidente Tancredo Neves, 2501, CEP 66077-530, Belém - PA, Brasil \\ ${ }^{3}$ Departamento de Morfologia da Faculdade de Ciências Agrárias e Veterinária \\ Universidade do Estado de São Paulo, Jaboticabal - SP, Brasil \\ ${ }^{4}$ Departamento de Morfologia, Centro Universitário da Fundação Educacional de Barretos \\ Barretos - SP, Brasil \\ *Autor para correspondência \\ ebranco.ufra@gmail.com
}

Submetido em 01/03/2013

Aceito para publicação em 11/07/2013

\section{Resumo}

A paca (Cuniculus paca) é uma espécie de roedor da família Cuniculidae, encontrada na América do Sul, desde a Bacia do Rio Orinoco até o Paraguai. Apesar de amplamente estudada quanto aos aspectos morfológico e reprodutivo, ainda não há registros sobre a morfologia do aparelho reprodutor masculino dessa espécie. Assim, objetivou-se avaliar não só a anatomia macro e microscópica dos órgãos genitais externos dessa espécie, mas, também, sua topografia. Foram estudados os órgãos genitais externos de 10 pacas, machos, adultas; 5 espécimes, fixados em solução aquosa de formol a 10\%, foram estudados macroscopicamente e de 5 espécimes foram coletados fragmentos do aparelho reprodutor, para análise microscópica. Os testículos apresentavam parênquima estruturado em túbulos seminíferos e o epitélio germinativo repousava sobre sua membrana basal. Esses órgãos estavam localizados na cavidade abdominal, no trajeto inguinal ou no interior do escroto. O pênis, fibroelástico, localizava-se na região púbica, em direção caudal. Sua glande, revestida por epitélio queratinizado, era recoberta pelo prepúcio e, abaixo deste, identificou-se uma estrutura delgada cartilagínea com bordas serreadas. Um par de esporões ósseos abrigava-se em um saco ventral à uretra, cuja mucosa era revestida por epitélio de transição. O ducto epididimário apresentava-se enovelado na cabeça, continha corpo e cauda, sendo a cabeça revestida por epitélio pseudoestratificado estereociliado, e a cauda por epitélio cúbico simples; desta originava-se o ducto deferente, revestido por epitélio estratificado colunar.

Palavra-chave: Morfologia; Órgão reprodutor masculino; Paca 


\section{Abstract}

Morphology and topography of the external male genital organs of spotted paca (Cuniculus paca Linnaeus, 1766). Spotted paca (Cuniculus paca) is a rodent species from the family Cuniculidae, found in South America, from the Orinoco River Basin to Paraguay. Although widely studied with regard to its morphological and reproductive aspects, still there're no records on the morphology of the male reproductive system in this species. Thus, this study aimed to evaluate not only the macro and microscopic anatomy of the external genital organs in this species, but also their topography. We studied the external genital organs of 10 adult spotted pacas; 5 specimens, fixed in a $10 \%$ aqueous formaldehyde solution, were macroscopically studied and from 5 specimens we collected fragments from the reproductive system, for microscopic analysis. The testicles showed a parenchyma structured in seminiferous tubules and the germinal epithelium rested on its basal membrane. These organs were located in the abdominal cavity, the inguinal path, or within the scrotum. Penis, fibroelastic, was located in the pubic region, in caudal direction. Its glans, coated by keratinized epithelium, were covered by the prepuce and, below this, we identified a slender cartilaginous structure with serrated edges. A couple of bone spurs was located into a bag ventral to the urethra, whose mucosa was lined by transitional epithelium. The epididymal duct was balled up in the head, had a body and tail, and its head was lined by pseudo-stratified stereociliated epithelium, and the tail by simple cubic epithelium; from this, the deferent duct stemmed, lined by columnar stratified epithelium.

Key words: Male reproductive organ; Morphology; Spotted paca

\section{Introdução}

A paca (Cuniculus paca) é o terceiro maior roedor do Brasil, sendo a capivara, o primeiro, pertencente à classe Mammalia; Ordem Rodentia, gênero Cuniculus (QUEIROLO et al., 2008).

Espécie de corpo robusto (COLLET, 1981), com cabeça grande e larga, membros curtos, dedos alongados providos de garras e cauda reduzida (BONVICINO et al., 2008), podendo atingir $80 \mathrm{~cm}$ de comprimento, 12 $\mathrm{kg}$ de peso corpóreo (PACHALY et al., 2001) e 16 anos de tempo médio de sobrevida (LANGE; SCHMIDT, 2007, QUEIROLO et al., 2008). São animais frugívoros, mas podem consumir outros vegetais e até insetos em períodos de escassez alimentar (DUBOST; HENRY, 2006).

Geograficamente a paca está distribuída do Sudoeste do México ao Sul do Brasil, vivendo em áreas cobertas com vegetação alta, tais como matas e capoeirões, sempre próximos aos rios ou riachos, pois estes animais têm o costume de mergulhar (SILVA, 1994).

Entre os mamíferos silvestres do neotrópico a paca é a mais apreciada por sua carne (REDFORD; ROBINSON, 1991) contribuindo como importante fonte proteica para população de áreas marginais de florestas e reservas. O Brasil, assim como outros países, possuem criatórios autorizados pelo Instituto Brasileiro do Meio Ambiente e dos Recursos Naturais Renováveis (IBAMA), para esses fins comerciais (FIEDLER, 1990; MOCKRIN et al., 2005).

Com relação aos órgãos reprodutores masculinos externos, alvos de nossa investigação, os roedores em geral, apresentam um pênis, par de testículos, um par de epidídimos, um par de ductos deferentes, um par de funículos espermáticos e uma uretra havendo pequenas variações entre as diferentes espécies (JUNQUEIRA; MARTINS, 1947; COOPER; SCHILLER, 1975; OLDS; OLDS, 1979; MENEZES et al., 2003; DYCE et al., 2010).

Pouco se sabe sobre os órgãos reprodutores masculinos externos de roedores selvagens, assim, diante da escassa literatura, este estudo foi embasado na literatura clássica sobre aparelho reprodutor masculino de roedores em geral.

Diante da importância que a paca representa como fonte de proteína de baixo custo e, considerando a escassez de informações sobre a morfologia reprodutiva desses animais, objetivou-se descrever a morfologia e a topografia dos órgãos genitais masculinos externos dessa espécie, colaborando com futuras investigações, principalmente aquelas relativas à exploração zootécnica racional destes roedores. 


\section{Materiais e Métodos}

Foram utilizados 10 animais (C. paca), oriundos do pacário pertencente ao Setor de Animais Silvestres do Departamento de Zootecnia da Faculdade de Medicina Veterinária de Jaboticabal - UNESP, o qual é registrado junto ao IBAMA, como criatório de espécimes da fauna brasileira para fins científicos (cadastro de registro 482508).

Este estudo esteve em concordância com os princípios éticos de experimentação animal adotado pelo Colégio Brasileiro de Experimentação Animal (COBEA) e foi aprovado pela Comissão de Ética no Uso de Animais (CEUA), protocolo ํㅜㅜ 014095/12.

Dos 10 animais utilizados, cinco foram a óbito por causas diversas, que não estavam correlacionadas com o aparelho reprodutor e cinco foram eutanasiados por meio de infusão intramuscular de azaperone ( $4 \mathrm{mg} / \mathrm{kg}$ ), seguida por infusão também intramuscular de cloridrato de quetamina $(20 \mathrm{mg} / \mathrm{kg})$ e cloridrato de xilazina $(1,5$ $\mathrm{mg} / \mathrm{kg}$ ) até a efetuação do óbito.

Para a descrição macroscópica e topográfica dos órgãos genitais masculinos externos foram utilizados cinco animais, os quais foram posicionados em decúbito dorsal para fotodocumentação, seguido de dissecação escrotal, testicular e peniana.

No que concerne a microscopia de luz, foram utilizados outros cinco animais, dos quais, após o óbito, foram coletados fragmentos do pênis e uretra, testículo, epidídimo e ducto deferente, sendo em seguida fixados com solução de formol 10\% e incluídos em historesina (Historesin ${ }^{\circledR}$-Leica/Germany) e em paraplast (Histosec ${ }^{\circledR}$ -Merck).

O material incluso em Historesin ${ }^{\circledR}$ foi cortado em micrótomo (Leica-RM 2155), com navalha de vidro, obtendo-se cortes de 1 a $3 \mu \mathrm{m}$, sendo corados com Hematoxilina-Phloxina B, Tricrômio de Masson e Azul de Toluidina a $1 \%$ e $0,5 \%$. Já no material incluso em Histosec $₫$, foi realizada a rotina histológica convencional e em seguida realizada a microtomia com micrótomo automático (Leica-RM 2155), com navalhas descartáveis, obtendo-se cortes de $5 \mu \mathrm{m}$, que foram corados com Hematoxilina-eosina, Heidanhain-
Sclleicher e reação de Periodic acid Schiff (PAS), seguindo as metodologias propostas por Behmer et al. (1976).

As preparações histológicas foram fotomicrografadas em fotomicroscópio (Olympus - BX-50) para documentação.

\section{Resultados}

\section{Morfologia macroscópica}

Todos os animais apresentaram um pênis com prepúcio, um par de testículos envoltos pelo escroto; um par de epidídimos; compostos de cabeça, corpo e cauda; um par de ducto deferente e uretra.

Ventromedialmente, na região púbica, em todos os animais analisados, observou-se uma elevação da cútis, a qual se abria caudalmente em um óstio ventral ao ânus, caracterizando o pênis revestido pelo prepúcio o qual se abria no óstio prepucial. Em quatro espécimes, não foi notado qualquer esboço externo do escroto e em um animal, foi possível identificar um escroto em cada lado (Figuras 1A e 1B).

A cútis da região escrotal apresentava a mesma característica da cútis de toda a região abdominal ventral e da inguinal, pêlos escassos de coloração amarelada (Figuras 1A e 1B). À dissecação foi possível evidenciar túnica dartos, aderida firmemente à cútis, tecido subcutâneo, fáscia espermática externa e interna, bolsa vaginal, cavidade vaginal, lâmina parietal e visceral da túnica vaginal e túnica albugínea testicular (Figura 1C).

Os testículos apresentaram-se como estruturas ovaladas, alongadas crânio-cauldalmente (Figura 1C-E), sendo que três das cinco amostras observadas situavamse na cavidade abdominal, próximos ao ânulo vaginal. Em uma amostra, o testículo direito situava-se no escroto e o esquerdo próximo ao ânulo inguinal profundo e em outra amostra os dois testículos apresentavam posição escrotal.

As gônadas mostravam extremidade capitada e caudada, e margem epididimária e livre. A extremidade capitada era arredondada e mais alargada que a extremidade caudada, voltada cranialmente, relacionando- 
se com a cabeça do epidídimo. A extremidade caudada, mais estreita, apresentava-se arredondada, em contato com a cauda do epidídimo. A margem epididimária era côncava, apresentando orientação medial e estava em íntima relação com o corpo do epidídimo, enquanto que a margem livre ou lateral apresentava-se convexa. A posição dos testículos na paca determinou uma face medial e outra lateral (Figura 1D).

Ao corte longitudinal, entre extremidade capitada e caudada, constatou-se que o testículo era revestido intimamente por uma cápsula espessa esbranquiçada, com a túnica albugínea emitindo septos para o interior do parênquima testicular, no sentido da periferia para o centro, dividindo-o em lóbulos testiculares. Estes septos uniam-se em posição axial, formando o mediastino testicular (Figura 1E).

A fixação testicular se deu na extremidade captada, por meio de componentes do funículo espermático, no qual a artéria testicular enovelada era entrelaçada pelo plexo pampiniforme. O mesórquio proximal e o peritônio formavam também ligamentos que fixavam o funículo espermático e o ducto deferente, denominados de mesofunículo e mesoducto deferente, respectivamente (Figura 2A).

A extremidade caudada do testículo também promoveu fixação do órgão, por meio do ligamento da cauda do epidídimo, o qual se originava da lâmina visceral da túnica vaginal, fixando-se na extremidade caudal da bolsa vaginal e se continuava revestindo a face interna dessa bolsa, agora como lâmina parietal da túnica vaginal (Figura 2B).

Quanto ao epidídimo, este estendeu-se da extremidade captada dos testículos até a sua extremidade caudada, posicionando-se dorsomedialmente, estando dividido em cabeça, corpo e cauda. O corpo não encontrava-se fixado a margem epididimária, formando

FIGURA 1: Fotomacrografia dos órgãos genitais masculino externos da paca (C. paca). Observar em A e B: região caudal da paca adulta em decúbito dorsal. Prepúcio recobrindo o pênis (p), região escrotal (*) e ânus (a). Observar demarcação visível do escroto em B (*). C: cútis da região escrotal rebatida (p), túnica dartos (d), fáscia espermática externa e interna (ei), bolsa vaginal (b), lâmina parietal da túnica vaginal (lp) e lâmina visceral da túnica vaginal comum (lv). D: face lateral do testículo (Fl), extremidade captada (Ec), cabeça do epidídimo (ce), extremidade caudada (Ea), cauda do epidídimo (ca), margem epididimária (cabeça de seta), corpo do epidídimo (cc), mesórquio distal (md), margem testicular livre (seta), bolsa vaginal (b), ducto deferente (d). E: Parênquima testicular de paca. Túnica albugínea (seta), septos (S), lobos testiculares (cabeça de seta), mediastino testicular (m). Barras de escala: $1 \mathrm{~cm}$ e (E): $0,5 \mathrm{~cm}$.
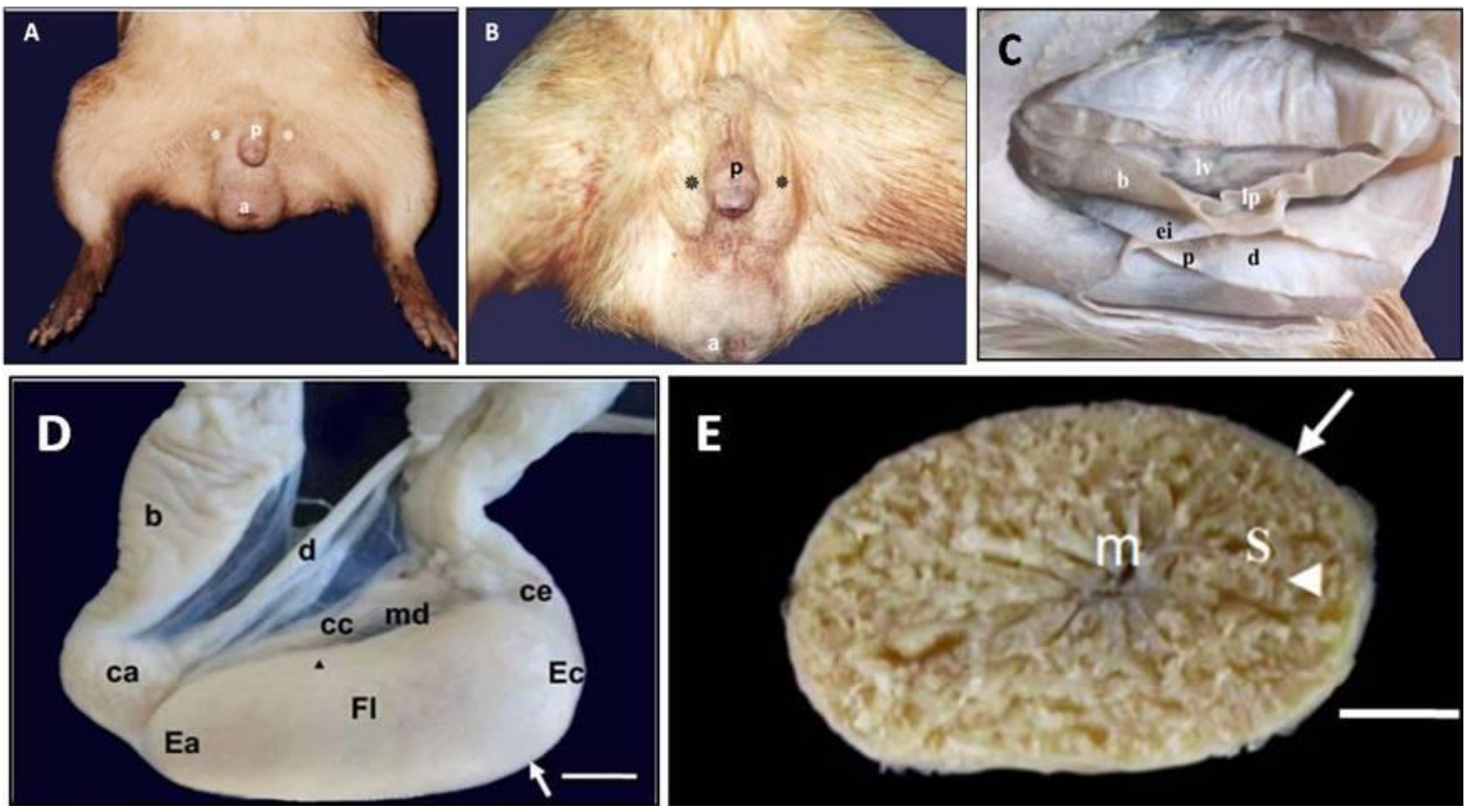
FIGURA 2: Fotomacrografia dos órgãos genitais masculino externos da paca (C. paca). Em A: funículo espermático. Observar artéria testicular (cabeça de seta), plexo pampiniforme (p), tecido adiposo $(*)$, mesofunículo (cabeça de seta), mesórquio proximal (mp), bolsa vaginal (bv), músculo cremaster (mc), ducto deferente (d) e testículo (t). Em B: extremidade caudada do testículo. Ligamento da cauda do epidídimo (le) continuando-se com a lâmina parietal da túnica vaginal (lp), aderida à face interna da bolsa vaginal (seta), ligamento próprio do testículo (lt) ligando este órgão à cauda do epidídimo (c). Em C: corte transversal do corpo peniano observa-se a túnica albugínea (ta) e os septos espessos desta túnica (seta), o corpo cavernoso (cc), artéria helicínia (cabeça de seta preta), o corpo esponjoso (ce), a uretra (u), os tendões dos esporões (t) e o tendão do músculo subisquiocavernoso (si). Em D: glande e prepúcio (Pr). Dorsalmente observar presença de uma lâmina cartilaginosa e queratinizada provida de espículas de tamanhos variados em suas margens (seta). Em E: porção ventro-lateral da glande com presença de estrutura sacular, formando o saco intromitente (seta). Em F: observar esporões rígidos (e) alojados no saco intromitente. Estes estão fixados por tendões que originam-se da porção caudal desses esporões e inserem-se na fáscia superficial em posição lateral (t).
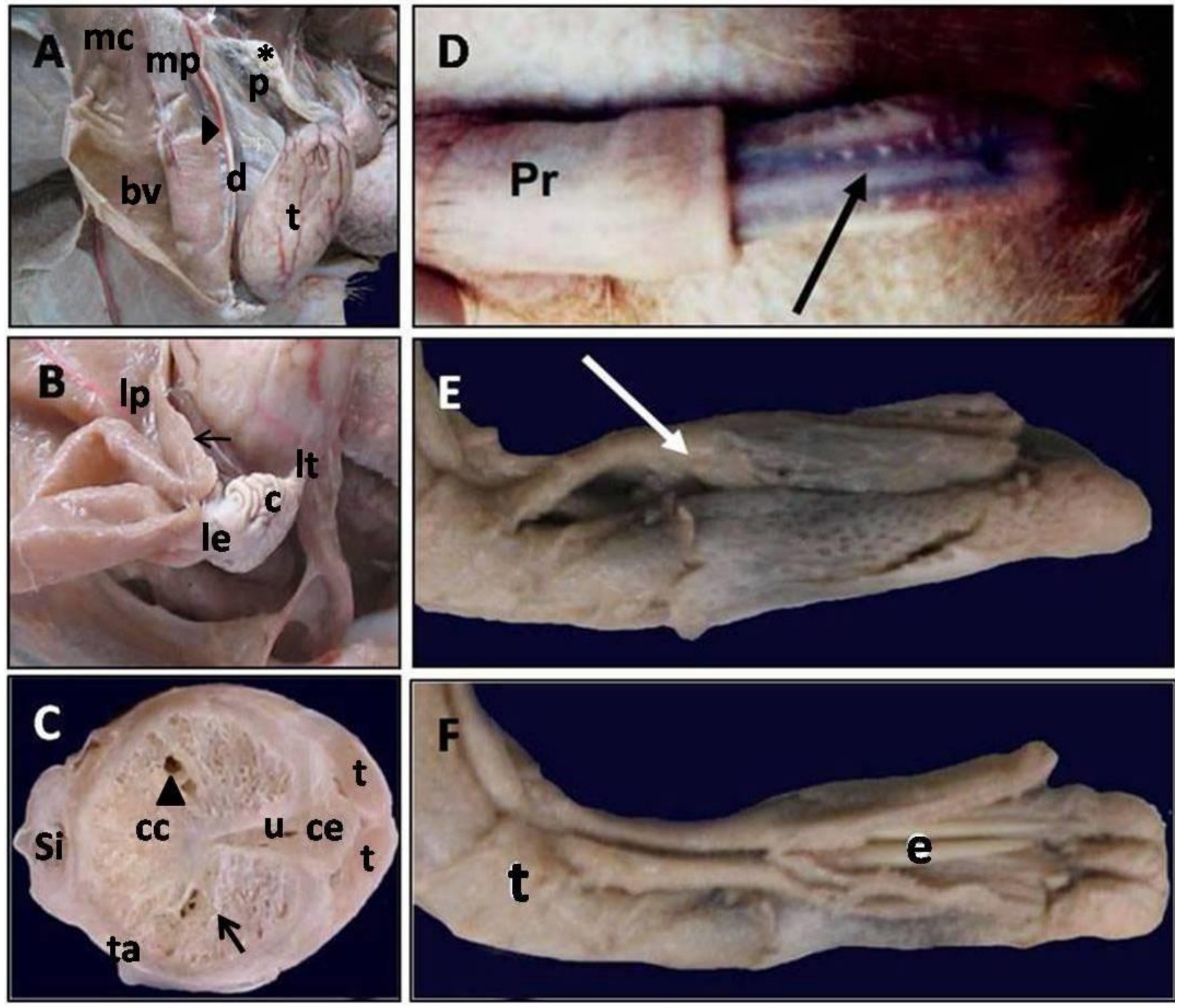
o seio do epidídimo. Já a cauda apresentou-se globosa, grande com ducto epididimário altamente convoluto (Figura 1D e 2B).

O ducto deferente da paca apresentou-se como um tubo relativamente reto, originando-se na margem caudomedial do epidídimo, envolto pela túnica vaginal do músculo cremaster, passando entre as glândulas prostáticas ventrais, dorsal a bexiga e ventral às glândulas vesiculares, desembocando isoladamente no colículo seminal da uretra pélvica, não caracterizando um ducto ejaculatório. Não foi constatada nenhuma dilatação do ducto, possuindo um diâmetro uniforme em todo seu segmento (Figura 1B e 2A).

Quanto à uretra da paca, esta apresentava dois segmentos (uretra pélvica e uretra peniana). A uretra pélvica localizava-se na cavidade pélvica, no plano mediano e ventral ao reto, estendendo-se do óstio uretral interno, no colo da bexiga onde se iniciava, até a raiz do pênis. No início da uretra se deu a desembocadura dos ductos deferentes e das glândulas genitais acessórias, na região do colículo seminal.

A uretra peniana teve início na raiz do pênis, estando amplamente contida no interior, para terminar na extremidade livre do órgão no óstio uretal externo, estando circundada pelo corpo esponjoso do pênis, tendo o seu trajeto ventral ao sulco uretral do corpo cavernoso.

Quanto ao órgão copulatório, macroscopicamente o pênis da paca apresentou uma curvatura caudal peniana em forma de "S" invertido, de maneira que sua parte apical se voltou caudalmente, terminando no ápice ou glande.

O corpo do pênis possuía forma cilíndrica e era formado por dois tipos de tecidos eréteis: o corpo cavernoso e o corpo esponjoso, sendo que, o corpo cavernoso localizava-se dorsalmente e mostrava-se revestido pela túnica albugínea desde a raiz do pênis, onde se iniciava, até próximo da região de transição entre o corpo peniano e a glande, local em que se transformava na lâmina óssea de margens espiculadas, dorsalmente ao corpo esponjoso e à uretra, logo abaixo do prepúcio (Figura 2E e 2F).

Ao analisar um corte transversal do corpo peniano da paca, constatou-se que seu corpo cavernoso possuía pequenos espaços sanguíneos divididos por quantidade volumosa de tecido fibroelástico rijo, derivado da túnica albugínea, o que o classificava como pênis fibroelástico, contendo no seu interior, grandes vasos de parede espessas, as artérias helicínias. O corpo esponjoso envolvia a uretra, apresentava espaços sanguíneos menores do que os do corpo cavernoso, sendo mais delicado do que este. Tanto o corpo cavernoso quanto o esponjoso estavam envoltos pelo músculo bulboesponjoso (Figura 2C).

Ao observar o aspecto dorsal de um corte longitudinal da glande, verificou-se a presença de uma estrutura sacular, no qual estavam alojados dois esporões rígidos com extremidades livres pontiagudas. Estes eram fixados por tendões que se originavam da porção caudal desses esporões e inseriam-se na fáscia superficial, em posição lateral, na altura da flexura peniana. Cranialmente a esta estrutura em fundo de saco cego havia uma pequena elevação, o tórus uretral (Figura 2F).

\section{Morfologia microscópica}

Em todos os testículos analisados, o parênquima estava envolto pela lâmina visceral da túnica vaginal, constituída de mesotélio e uma camada de tecido conjuntivo. Estas se aderiram à túnica albugínea de tecido conjuntivo denso regular, constituída predominantemente por fibras colágenas que emitiram septos para o interior desse parênquima testicular, dividindo-o em lóbulos testiculares, nos quais localizavam-se os túbulos seminíferos (Figura 3A).

Ainda no testículo, foi possível constatar a presença de células de Leydig na região interticial testicular, entre os túbulos seminíferos (Figura 3A). No interior destes túbulos, entre a lâmina basal e o seu lúmen, observou-se células espermatogênicas em diferentes fases do processo meiótico. Notou-se ainda, no interior destes túbulos, junto à parede interna destes, as células de Sertoli, as quais apresentavam citoplasma irregular, projetando-se entre as células da linhagem espermiogênicas no interior destes túbulos e núcleos triangulares (Figura 3B).

O ducto epididimário era formado por epitélio pseudo-estratificado cilíndrico estereociliado além de 
FIGURA 3: Fotomicrografia do aparelho reprodutor masculino de paca (C. paca). A e B: Testículo. Em A: túnica albugínea de tecido conjuntivo denso regular (Ag), septos (B) formando os túbulos seminíferos (C). Notar células mioepiteliais (seta) e células de Leydig (cabeça de seta). Em B: lâmina basal (seta) e lúmen dos túbulos seminíferos (*), espermátides (E), em diferentes estágios da espermiogênese e célula de Sertoli (S). C e D: Epidídimo. Em C: cabeça do epidídimo com epitélio pseudoestratificado estereociliado. Observar células apicais (seta preta), células basais (seta branca), células principais (cabeça de seta branca) e linfócitos (cabeça de seta preta). Em D: cauda do epidídimo com grande quantidade de espermatozoides na luz do túbulo $(*)$, revestido por epitélio cúbico simples (seta vazada), apoiado em camada de tecido conjuntivo e colágeno (seta), sustentada por tecido conjuntivo frouxo (cabeça de seta). Coloração: A - Heidenhain's (HS) 200x, B - Hematoxilina-Eosina (HE) 200x, C - Tricrômio de Masson 200x, D - Tricrômio de Masson 40x.
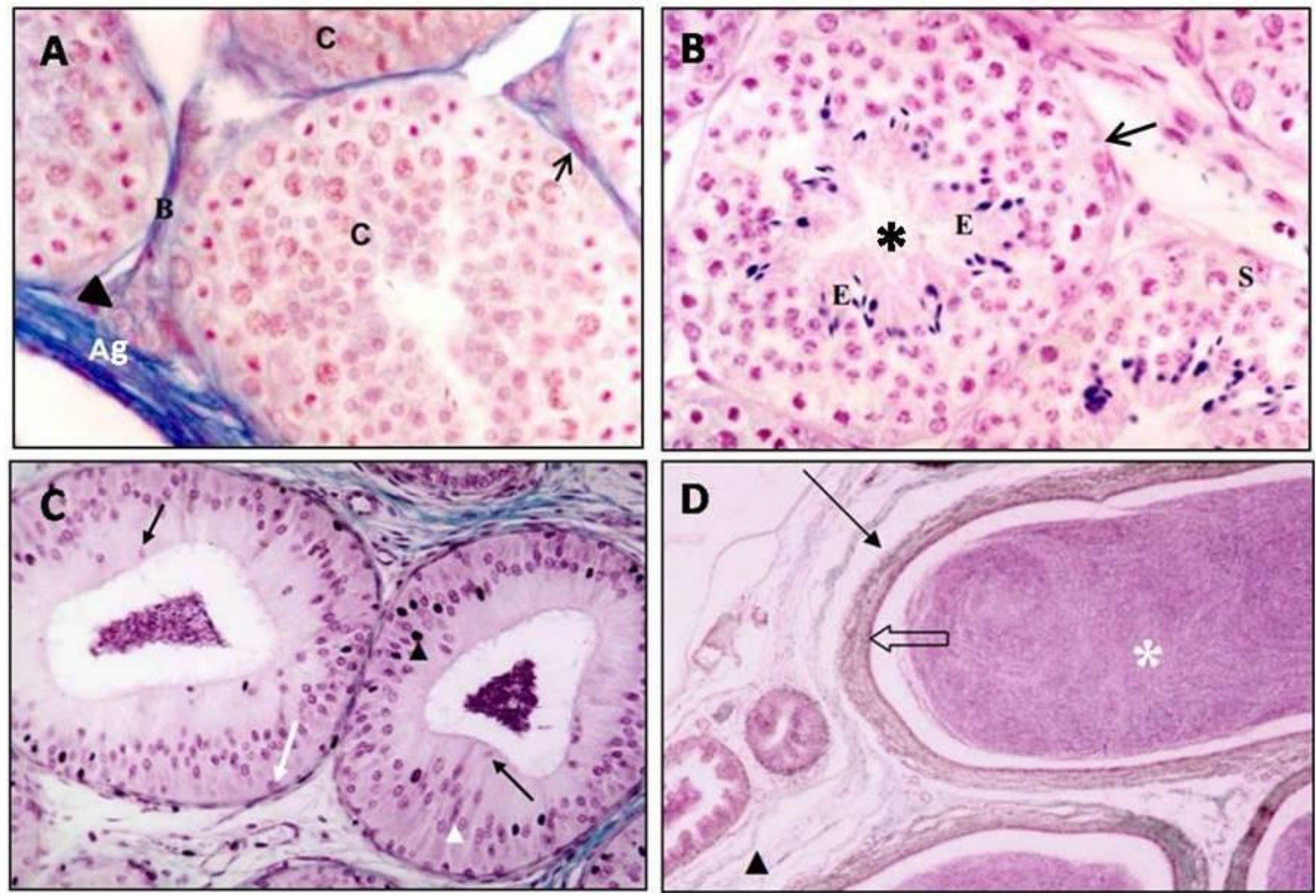

células principais, células basais e linfócitos intra-epiteliais (Figura 3C). A porção da cauda apresentou diâmetro menor, porém, com grande quantidade de espermatozoides presentes na luz do ducto epididimário. O epitélio desta região se apresentava cúbico simples sustentado por tecido conjuntivo frouxo ou denso (Figura 3D).

No que tange os ductos deferentes, estes eram formados por epitélio estratificado colunar estereociliado, com células variando de altas a baixas. Em sua porção inicial, até atingir a cavidade pélvica, este órgão estava revestido externamente por serosa, e sua porção final por adventícia (Figura 4A).

Analisando a uretra peniana à microscopia de luz, verificou-se que esta apresentava epitélio de transição apoiado em espessa camada de tecido conjuntivo frouxo irregular, entremeado por algumas fibras musculares (Figura 4B). Este tecido estava envolto pelo corpo esponjoso, cujos espaços eram delimitados por endotélio, também, apoiado em tecido conjuntivo frouxo.

No corpo do pênis, histologicamente, na paca, observou-se que a uretra estava revestida por epitélio de transição, sendo totalmente circundado pelo corpo esponjoso do pênis, que se diferenciava por apresentar espaços revestidos de endotélio entremeado de tecido 
FIGURA 4: Fotomicrografia dos órgãos genitais masculino externos da paca (C. paca). Em A: ducto deferente com epitélio estratificado colunar ciliado (seta vazada) e células basais (cabeça de seta). HE 200x. Em B: uretra peniana onde observa-se lúmen (*), epitélio de transição (seta) circundado pelo corpo esponjoso com seios ( $\star$ ) entremeados no tecido conjuntivo (cabeça de seta). HE. 200x. Em C: corpo do pênis com destaque para lúmen da uretra (*), corpo esponjoso com traços de tecido erétil, entremeados no tecido conjuntivo (tc), túnica albugínea do corpo cavernoso (ta) e corpo cavernoso com espaços cavernosos mais calibrosos (ec), entremeados de tecido conjuntivo denso (tcd). HE. 40x. Em D: corpo do pênis destacando tecido ósseo dorsal (to), lúmen uretral (*), corpo esponjoso (ce) e epiderme que reveste a glande, espessa, com camada córnea e projeções (seta). HE. 100x.
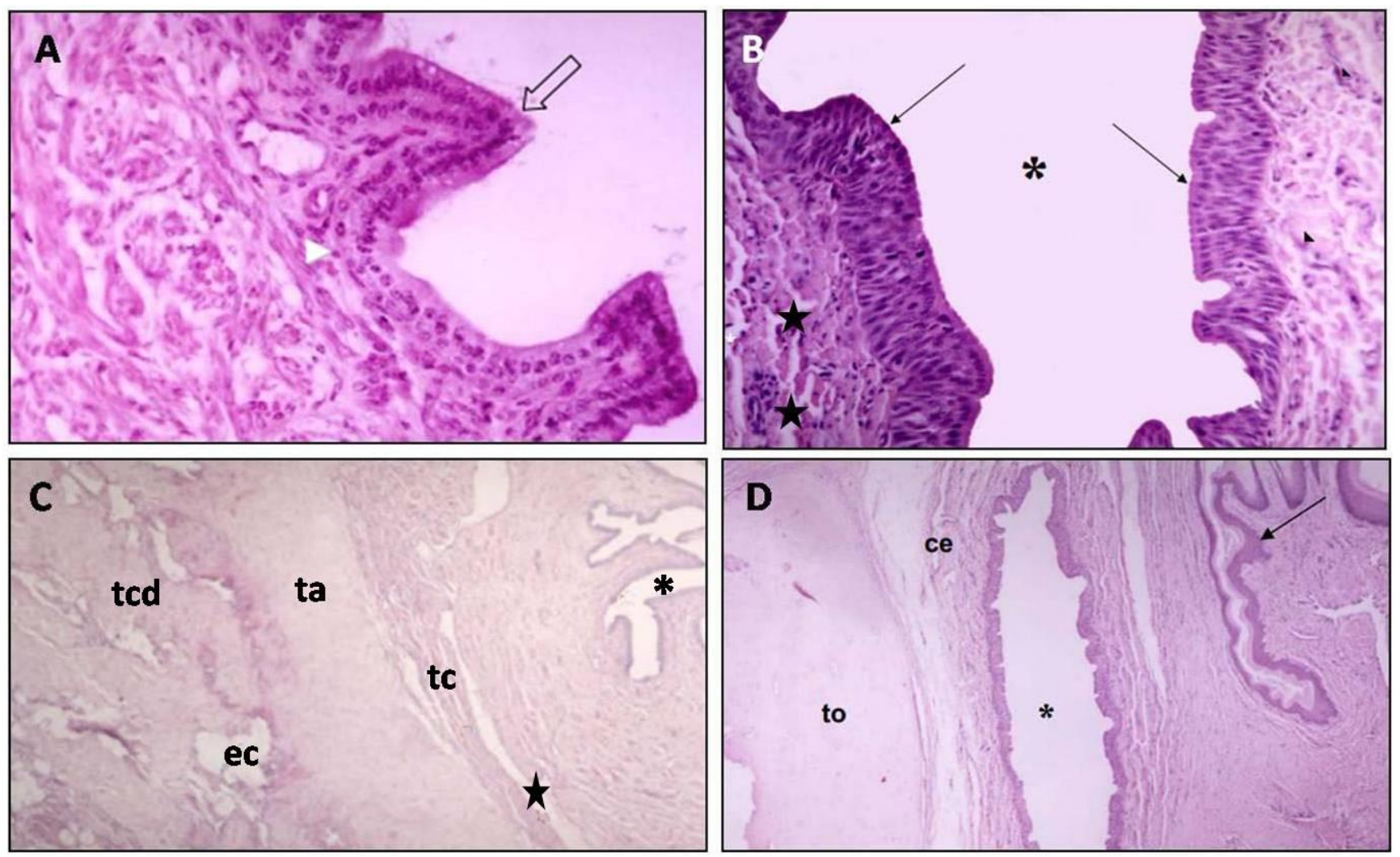

conjuntivo fibroelástico, caracterizando um tecido erétil. Este corpo esponjoso, juntamente com a uretra peniana, mostrou-se parcialmente envolto por uma bainha de tecido conjuntivo denso, que correspondia à continuação da túnica albugínea (Figura 4C).

A glande do pênis revelou um tecido ósseo dorsal, substituindo o corpo cavernoso, sendo o corpo esponjoso o único tecido erétil presente. A epiderme que revestia a glande era espessa com uma camada córnea expressiva que se caracterizava pela presença de projeções córneas (espículas) (Figura 4D).

\section{Discussão}

No âmbito geral, os órgãos genitais externos da paca apresentaram características anatômicas semelhantes às relatadas para rato (Rattus norvegicus) (JUNQUEIRA; MARTINS, 1947; OLDS; OLDS, 1979), cobaia (Cavia porcellus) (COOPER; SHILLER, 1975) e cutia (Dasyprocta aguti) (MENEZES et al., 2003).

Externamente, a genitália masculina da paca assemelhou-se ao descrito por Barone et al. (1973) para coelhos (Oryctolagus cuniculus), no qual o escroto localizava-se na região inguinal, lateralmente ao pênis. Porém, na paca estas estruturas só são evidenciadas na época da reprodução (COLLET, 1981), quando os testículos migram da cavidade abdominal por meio do 
trajeto inguinal, localizando-se em seus respectivos escrotos, os quais estavam posicionados ventralmente ao ânus, tal qual descrito por Chiasson (1969) em ratos e por Menezes et al. (2003) em cutias. Estes resultados contestam daqueles descritos por Hillyer e Quesenberry (1997) para coelho, nos quais os autores afirmaram que os escrotos localizavam-se cranialmente ao pênis.

Numa visão mais interna, a estratigrafia escrotal da paca diferiu ligeiramente de outros roedores, uma vez que não se descreveu a presença de uma bolsa vaginal, mas sim de uma túnica vaginal (CHIASSON, 1969; BARONE et al., 1973) ou processo vaginal (COOPER; SCHILLER, 1975). A bolsa vaginal foi observada por Menezes et al. (2003) na cutia, embora, nesta espécie, esta era formada de fibras do músculo cremaster assim como foi observado na paca, sendo este originado dos músculos externos e internos do abdome.

Os testículos da paca apresentaram-se com formato ovalado, porém, alongado diferindo do descrito no camundongo de laboratório (Mus musculus) (COOK, 1965; HEBEL; STROMBERG, 1986) e na observação de Matamoros (1981) para esta mesma espécie, no qual os testículos eram apenas ovalados, mas não alongados. $\mathrm{O}$ formato testicular da paca assemelhou-se mais com o formato testicular da cutia (MENEZES et al., 2003).

Ainda quanto às gônadas masculinas da paca, estas eram sustentadas e nutridas pelos componentes do funículo espermático, da mesma forma que ocorreu no rato ( $R$. norvegicus), coelho (O. cuniculus), cutia (D. aguti), preá (Galea spixii spixii) e camundongo (M. musculus) (CHIASSON, 1969; BARONE et al., 1973; BORELLI; GONÇALVES, 1999a; 1999b; CARVALHAL et al., 2000).

Microscopicamente, os testículos da paca eram envoltos por um tecido conjuntivo denso regular, formando a túnica albugínea, também descrita por Junqueira e Martins (1947) nos testículos do rato.

Do ponto de vista arquitetônico, os testículos da paca assemelharam-se a descrição nesta mesma espécie feita por Matamoro (1981), aos do rato ( $R$. norvegicus) JUNQUEIRA; MARTINS, 1947; GUDE et al., 1982; HEBEL; STROMBERG, 1986; TAKANO; ABE, 1987;
GUNAY et al., 1998), aos do rato de laboratório ( $R$. norvegicus) (GUDE et al., 1982), aos dos ratos adultos ( $R$. norvegicus) (TAKANO; ABE, 1987) e aos do rato de areia (Psammomys obesus) (SPRANDO et al., 1999).

Assim como no parênquima testicular do Calomys musculinus, os testículos da paca revelaram grande quantidade de células de Leydig, porém, não foi notada a formação de agrupamento destas células como o observado na espécie citada (BUZZIO; CASTROVAZQUES, 2002).

O epidídimo da paca apresentou-se dividido em cabeça, corpo e cauda, sendo tubular e convoluto, assim como descrito na literatura para outros roedores, com conformação tanto de cabeça quanto de cauda semelhante aos demais roedores (GRIFFITH; FARRIS, 1942; JUNQUEIRA; MARTINS, 1947; OLDS; OLDS, 1979; COOK, 1965; CHIASSON, 1969; BARONE et al., 1973; COOPER; SCHILLER, 1975; MATAMOROS, 1981).

Quanto ao corpo do epidídimo, na paca, este correspondia à sua porção mais delgada, observação concordante com as citações de Griffith e Farris (1942) para o rato, o mesmo encontrava-se parcialmente fixo a margem epididimária do testículo, da mesma forma que ocorre em coelho (BARONE et al., 1973) e em rato (JUNQUEIRA; MARTINS, 1947).

Entre o corpo do epidídimo e a margem epididimária do testículo, ainda na paca, encontrou-se um espaço interposto, o seio do epidídimo, no qual se observou uma membrana serosa derivada do peritônio, o mesórquio distal, que mantinha o epidídimo fixo à margem epididimária do testículo. Ambas as estruturas não foram referenciadas por nenhum dos autores da literatura consultada.

O mesmo revestimento epitelial observado na cabeça do epidídimo, onde se localizavam os ductos eferentes e a porção inicial do ducto epididimário da paca, foi descrito por Matamoros (1981) para a mesma espécie e para a capivara (Hydrochoerus hydrochaeris) (PAES-DE-BARROS et al., 2000), porém, os autores não fizeram referência ao ducto eferente e também descrevem, diferentemente do epitélio cúbico simples que ora foi observado na paca, um revestimento epitelial 
do tipo pseudo-estratificado para capivara e colunar simples para a paca na região da cauda do epidídimo. Este último tipo de epitélio também foi observado no ducto epididimário do rato gigante da Índia (Microperoryctes murina) (AMIYA; MAITI, 1982).

No que tange o ducto deferente, a literatura consultada é unânime em afirmar que este órgão é oriundo da cauda do epidídimo, fato também constatado na paca, sendo convencionalmente dividido em três partes: porção inicial, porção média e porção distal. No rato ( $R$. norvegicus) em duas partes: proximal e distal (KENNEDY; HEIDGER JR., 1979), na cobaia também em duas, porém, chamadas de epididimal e reta (COOPER; SCHILLER, 1975).

Tanto no coelho (BARONE et al., 1973) quanto no rato (HAMILTON; COOPER, 1978) o ducto deferente desembocou na uretra e uniu-se aos tubos das glândulas vesiculares, formando uma estrutura denominada ducto ejaculatório. Este fato não foi registrado na paca, uma vez que o ducto deferente e os tubos das glândulas vesiculares desembocavam separadamente na uretra.

O epitélio do ducto deferente na paca mostrou-se estratificado colunar estereociliado, diferindo daquele apresentado no rato gigante da Índia (M. murina) (AMIYA; MAITI, 1982) e no rato ( $R$. norvegicus) (NIEMI, 1965), espécies em que o epitélio foi identificado como pseudo-estratificado com esteriocílios proeminentes.

Quanto ao pênis, na paca foi possível detectar a presença de osso peniano, algumas vezes denominado de baculum, assim como é registrado nos roedores em geral (ANGULO; ALVAREZ, 1948; OJASTI, 1973; COOPER; SCHILLER, 1975; WAGNER; MANNING, 1976; MATAMOROS, 1981; CAVALCANTE FILHO et al., 1996; MENEZES et al., 2003), porém, na paca, o osso peniano estava em continuação ao corpo cavernoso do pênis, disposto dorsalmente à glande, como descrito por Griffith e Farris (1942), ao descreverem o pênis do rato.

Ainda na paca, o osso peniano apresentou bordas com formação de espículas queratinizadas de variados tamanhos, indo de encontro com os achados de Matamoros (1981), também na paca e de Cavalcanti
Filho et al. (1996) e de Menezes et al. (2003) na cutia. Outras descrições referiam-se apenas à presença de espículas na glande, como relatou Pocock (1922) ao descrever que a superfície da glande da maioria dos Histricomorfos era coberta por espículas, dando-lhe um aspecto áspero e também conforme as descrições para o rato (JUNQUEIRA; MARTINS, 1947), o hutia (Capromys pilotides) (ANGULO; ALVAREZ, 1948), a capivara (OJASTI, 1973), a cobaia (COOPER; SHILEER, 1975) e o rato de laboratório (HEBEL; STROMBERG, 1986).

Nas espécies comprovadamente de ovulação induzida, que incluem coelhos, roedores, ferrets, visons, lhamas, alpacas, camelos, dromedários e gatos domésticos a ovulação ocorre na dependência da cópula (BAKKER; BAUM, 2000). Para este fato, chama a atenção as particularidades inerentes aos órgãos copulatórios, tanto da paca macho, ora estudado, que caracterizou-se pela presença de lâmina cartilaginosa e queratinizada de margens espiculadas, além de rígidos esporões com extremidade livre pontiaguda, quanto da paca fêmea, no qual são observadas na região do clitóris, ventralmente à abertura uretral, a presença de duas estruturas pontiagudas, semelhantes a espinhos (REIS et al., 2011). Contudo, não foi observada na literatura especializada qualquer alusão quanto à morfofisiologia dessas estruturas para a paca.

Histologicamente, o pênis da paca apresentouse semelhante ao da cutia, conforme as descrições de Menezes et al. (2003), pois se verificou uma camada de tecido conjuntivo denso compondo a túnica albugínea do corpo esponjoso. Todavia, o pênis da paca não foi classificado como fibrocavernoso, tal qual nomeado por Menezes et al. (2003) em cutia, pois mesmo tendo constatado a presença de tecido erétil esponjoso e cavernoso constituindo o pênis da paca, não observou preponderância dos espaços vasculares na estruturação do tecido erétil.

O epitélio que revestiu a uretra, na paca, era do tipo de transição e este mesmo tipo de epitélio foi observado por Junqueira e Martins (1947) na uretra do rato e por Pinheiro et al. (2003) na uretra pélvica, próximo ao colo da bexiga. 
De forma geral, pode-se afirmar que os órgãos genitais masculinos externos da paca, assemelham-se ao preconizado na literatura clássica para roedores em geral, salvaguardando a presença de dois esporões, fato até então registrado somente em cutias.

\section{Referências}

AMIYA, P. S. H.; MAITI, B. R. Quantitative studies of the reproductive organs of the male bandicoot rat - A common rodent pest. Anatomischer Anzeiger, Erlangen, v. 151, n. 5, p. 483-495, 1982.

ANGUlO, J. J.; ALVAREZ, M. T. The genital tract of the male conga hutia, Capromys pilorides (Say). Journal of Mammalogy, Connecticut, v. 29, n. 3, p. 277-285, 1948.

BAKKER, J.; BAUM, M. J. Neuroendocrine regulation of GnRH release in induced ovulators. Front. Neuroendocrinology, Edinburgh, v. 21, p. 220-262, 2000.

BARONE, R.; PAVAUX, C.; BLIN, P. C.; CUQ, P. Atlas d'anatomie du lapin. Paris: Masson, 1973. 219 p.

BEHMER, O. A.; TOLOSA, E. M. C.; FREITAS NETO, A. G. Manual de técnicas para histologia normal e patológica. São Paulo: Editora da Universidade de São Paulo, 1976. 241 p.

BORELLI, V.; GONÇALVES, A. M. M. Aspectos morfológicos do funículo espermático da cutia (Dasyprocta prymnolopha). Revista do Instituto de Ciências da Saúde, São Paulo, v. 17, n. 1, p. 37 45, 1999a.

BORELLI, V.; GONÇALVES, A. M. M. Aspectos morfológicos do funículo espermático de preá (Galea spixil). Revista do Instituto de Ciências da Saúde, São Paulo, v. 17, n. 2, p. 79-87, 1999b.

BOVINCINO, C. R.; OLIVEIRA, J. A.; D’ANDREA, P. S. Guia dos roedores do Brasil, com chaves para gêneros baseados em caracteres externos. Rio de Janeiro: Centro Pan-Americano de Febre Aftosa - OPAS/OMS, 2008. 120 p.

BUZZIO, O. L.; CASTRO-VÁZQUEZ, A. Reprodutive biology of the corn mouse, Calonys musculinus, a neotropical sigmodontine. Journal of Neotropical Mammalogy, Puerto Madryn, v. 9, n. 2, p. 135-158, 2002.

CARVALHAL, R.; BORELli, V.; MONTEIRO, C. R. M.; LACERDA, C. M. J. Estudos anatômicos dos funículos espermáticos em coelhos (Octolagus cuniculus). Brazilian Journal of Morphological Science, São Paulo, v. 17, p. 104-105, 2000.

CAVALCANTE FILHO, M. F.; CARVALHO, M.A. M.; MIGLINO, M. A. Estudo morfológico do pênis da cutia (Dasyprocta agouti). In: CONGRESSO BRASILEIRO DE ANATOMIA, 17, 1996, Fortaleza. Anais... Fortaleza: SBA, 1996. p. 94.

CHIASSON, R. B. Laboratory anatomy of the white rat. 2. ed. Arizona: Wm. C. Brown, 1969. 81 p.

COLLET, S. F. Population characteristics of Agouti paca (Rodentia) in Colombia. Michigan State University, Biological Series, Michigan, v. 5, n. 7, p. 601, 1981.

COOK, M. J. The anatomy of the laboratory mouse. London: Academic Press. 1965. 143 p.
COOPER, G.; SCHILlER, A. L. Anatomy of the guinea pig. Cambridge: Harvard University Press, 1975. 417 p.

DUBOST, G.; HENRY, O. Comparison of diets of the acouchy, agouti and paca, the three largest terrestrial rodents of French Guianan forests. Journal of Tropical Ecology, Cambridge, v. 22, p. 641-651, 2006.

DYCE, K. M.; SACK. W. O.; WESING, C. J. G. Tratado de anatomia veterinária. 4. ed. Rio de Janeiro: Guanabara Koogan, 2010. 840 p.

FIEDLER L. A. Rodents as a food source. In: DAVIS, L. R; MARSH R. E. (Ed.). Vertebrate Pest Conference Proceedings Collection. Davis: University of California Press, 1990. p. 148-155.

GRIFFITH, J. Q.; FARRIS, E. J. The rat in laboratory investigation. Philadelphia: J. B. Lippincott, 1942. 448 p.

GUDE, W. D.; COSGROVE, G. E.; HIRSCH, G. P. Histological atlas of the laboratory mouse. New York: Plenum Press, 1982. $151 \mathrm{p}$.

GUNAY, Y.; BULUT, H. E.; ONARLIOGLUS, B.; BASIMOGLUKOCA, Y. Comparison of the effects of vasectomy and experimental cryptorchidism in rats: I. Testicular Histology. Okajimas Folia Anatomica Japonica, Tokyo, v. 75, n. 2-3, p. 61-70, 1998.

HAMILTON, D. W.; COOPER, T. G. Gross and histological variations along the length of the rat vas deferents. The Anatomical Record, Malden, v. 190, n. 4, p. 795-810, 1978.

HEBEL, R.; STROMBERG, M. V. Anatomy and embriology of the laboratory rat. Wörthesee: BioMed Verlag, 1986. 270 p.

HILLYER, E. V.; QUESENBERRY, K. E. Ferrets, rabbits, and rodents: clinical medicine and surgery. Philadelphia: W. B. Saunders, 1997. 432 p.

JUNQUEIRA, L. C. U., MARTINS, E. O. Atlas de anatomia microscópica do rato. São Paulo: Tipografia Rossolillo, 1947. $142 \mathrm{p}$.

KENNEDY, S.; HEIDGER JR., P. M. Fine structural studies of the rat vas deferens. The Anatomical Record, Malden, v. 194, n. 1, p. 159-180, 1979.

LANGE, R. R.; SCHMIDT, E. M. S. Rodentia: roedores silvestres (capivara, cutia, paca, ouriço). In: CUBAS, Z. S.; SILVA, J. C. R.; CATÃO-DIAS, J. A. (Ed.). Tratado de animais selvagens: medicina veterinária. São Paulo: Roca, 2007. p. 475-491.

MATAMOROS, Y. Anatomia y histologia del sistema reproductor del tepezcuinte (Cuniculus paca). Revista de Biologia Tropical, San Jose, v. 29, n. 1, p. 155-164, 1981.

MENEZES, D. J. A.; CARVALHO, M. A. M.; ASSIS-NETO, A. C.; OLIVEIRA, M. F.; FARIAS, E. C.; MIGLINO, M. A.; MEDEIROS, G. X. Morfologia dos órgãos genitais externos do macho de cutia (Dasyprocta aguti Linnaeus, 1766). Brazilian Journal of Veterinary Research Animal Sciense, São Paulo, v. 40, n. 2, p. 148-153, 2003. MOCKRIN, M. H.; BENNET, E. L.; LABRUNA, D. T. Wildlife farming: a viable alternative to hunting in tropical forests? New York: WCS Working Paper, Wildlife Conservation Society, n. 23, 2005. $32 \mathrm{p}$.

NIEMI, M. The fine structure and histochemistry of the epithelial cells of the rat vas deferens. Acta Anatomica, Basel, v. 60, n. 1, p. 207-219, 1965. 
OJASTI, J. Estudio biológico del Chiguira o Capibara. Caracas: Ediciones dei Fondo Nacional de Investigaciones Agropecuárias, $1973.275 \mathrm{p}$.

OLDS, R. J.; OLDS, J. R. A colour atlas of the rat: dissection guide. London: Wolfe Medical, 1979. 112 p.

PACHALY, J. R.; ACCO, A.; LANGE, R. R.; NOGUEIRA, T. M. R.; NOGUEIRA, M. F.; CIFFONI, E. M. G. Order Rodentia (Rodents). In: FOWLER, M. E.; CUBAS, Z. S. (Ed.). Biology, medicine, and surgery of south american wild animals. 1 ed. Iowa: Iowa State University Press, 2001. p. 225-237.

PAES-DE-BARROS, M. A. F.; RONDON, A. S.; PERSONA, L. N.; SIMÕES, M. J. Morfologia microscópica do epidídimo de capivara Hidrochoerus hidrochaeris. Brazilian Journal of Morphology Science, São Paulo, v. 17, p. 158, 2000.

PINHEIRO, P. F. F.; ALMEIDA, C. C. D.; SEGATELLI, T. M.; MARTINEZ, M.; PADOVANI, C. R.; MARTINEZ, F. E. Structure of the pelvic and penile urethra - relationship with the ducts of the sex accessory glands of the Mongolian gerbil (Meriones unguiculatus). Journal of Anatomy, Maiden, v. 202, p. 431-444, 2003.

POCOCK, R. I. On the external characters of some hystricomorph rodents. Proceeding Zoological Society, London, n. 25, p. $365-$ 427, 1922.
QUEIROLO, D.; VIEIRA, E.; EMMONS, L.; SAMUDIO, R. Cuniculus paca. In: IUCN 2010. IUCN Red List of Threatened Species. 2008. Disponível em: <www.iucnredlist.org > Acesso em: 28 mar. 2010.

REDFORD, K. H.; ROBINSON, J. G. Neotropical wildlife use and conservation. Chicago University of Chicago Press, 1991. $538 \mathrm{p}$.

REIS, A. C. G.; GERBASI, S. H. B.; MARTINS, C.; MACHADO, M. R. F.; OLIVEIRA, C. A. Morfologia do sistema genital feminino da paca. Brazilian Journal of Veterinary Research and Animal Science, São Paulo, v. 48, p. 1-4, 2011.

SILVA, F. Mamíferos silvestres do Rio Grande do Sul. 2. ed. Porto Alegre: Fundação Zoobotânica do Rio Grande do Sul, 1994. $264 \mathrm{p}$.

SPRANDO, R. L.; COLLINS, T. F. X.; BLACK, T. N.; OLEJNIK, N.; RORIE, J. L.; WEST, L. J.; BOWERS, J. D.; SASS, N.; ROBL, M. Light microscopic observations on the reproductive tract of the male sand rat, Psammomys obesus. Tissue and Cell, Siena, v. 32, n. 1, p. 99-115, 1999.

TAKANO, H.; ABE, K. Age-relted histologic changes in the adult mouse testis. Archives Histological Japanese, Nigata, v. 50, n. 5, p. 533-544, 1987.

WAGNER, J. E.; MANNING, P. J. The Biology of the Guinea Pig. New York: Academic Press, 1976. 317 p. 